\title{
Excessive menstruation bleeding as a presentation of dengue hemorrhagic fever
}

\author{
Somsri Wiwanitkit • Viroj Wiwanitkit
}

Received: 31 August 2012/Accepted: 22 November 2012/Published online: 30 November 2012

(C) Springer-Verlag Berlin Heidelberg 2012

\section{Dear Sir,}

Dengue is a well-known tropical viral infection that can result in bleeding abnormality due to severe thrombocytopenia. However, a rare presentation can be sometimes detected in clinical practice [1]. The gynecological bleeding is of interest. In sexually active women, dengue can co-present with menstruation and this can lead to severe dysmenorrhea and excessive menstrual bleeding [2]. Here, the authors would like to present a case study. The present case is a 20 -year-old female patient presenting with excessive menstruation for 2 days. She soaked more than 20 soaked sanitary pads per day and felt severe abdominal pain. This case was firstly diagnosed to be a case of hypermenorrhea and dysmenorrhea. At the first visit, the patient had fever (body temperature $38{ }^{\circ} \mathrm{C}$ ). The supportive treatment was given. However, the symptoms did not improve and the patient visited to the physician again 2 days later with high fever $\left(38.5^{\circ} \mathrm{C}\right)$ and low blood pressure (BP $90 / 50 \mathrm{mmHg}$ ). Due to severe illness, the case was consulted for examination of the cause of bleeding. There were many petechiae on limbs of the patient. The investigation showed thrombocytopenia (platelet count $40,000 / \mathrm{mm}^{3}$ ). Further investigation showed positive dengue serology test. This case was finally diagnosed to be a case with dengue hemorrhagic fever. The patient was hospitalized for fluid

\footnotetext{
S. Wiwanitkit $(\bowtie)$

Wiwanitkit House, Bangkhae, Bangkok, Thailand

e-mail: somsriwiwan@hotmail.com

V. Wiwanitkit

Hainan Medical University, Haikou, China

V. Wiwanitkit

Joseph Ayo Babalola University, Ilesa, Nigeria
}

replacement therapy and the clinical improvement was seen within 3 days. There was no complication at discharge. This case can be a good case study that dengue can present with uncommon bleeding and it can be overlooked. Indeed, dengue infection is already mentioned as a cause of menorrhagia in some reports $[2,3]$. However, this problem is limitedly recognized by practitioners. In the present case, the gynecologist missed the dengue due to the co-presentation with menstruation. For management of bleeding complaint in dengue endemic area, "physicians should not overlook bleeding from other less common sites such as the gastrointestinal tract and genitourinary tract [1]." On the other hand, physician should seek for underlying coagulopathy and its possible causes in any patients presenting with menorrhagia. Although dengue is rare in Europe, the important immigration rate within recent years might induce the possibility to find the disease even in European emergency units. Finally, the interesting issue left is on the percentage of women with menorrhagia as the first presentation of dengue fever. In a previous report by Wiwanitkit [1] in Thailand, 1 from 30 dengue patients had menorrhagia as the first clinical presentation.

Conflict of interest None.

\section{References}

1. Wiwanitkit V (2004) Bleeding and other presentations in Thai patients with dengue infection. Clin Appl Thromb Hemost 10(4):397-398

2. Tangnararatchakit K, Chuansumrit A, Chaiyaratana W, Lertwongrath S, Gajaseeni N, Udomchaisakul R, O-Prasertsawat $\mathrm{P}$, Yoksan S (2010) Excessive menstrual bleeding in adolescents with dengue infection. Pediatr Infect Dis J 29(1):92-93

3. Jain M, Sehgal A (2011) Dengue fever as a cause of menorrhagia. J Gynaecol Obstet 113(3):247-248 